\title{
Computer-Aided Analysis of Gas Turbine Exergy
}

\author{
Jewo $\mathrm{AO}^{1}$, Oyejide $\mathrm{OJ}^{2 *}$
}

${ }^{1}$ Department of Mechanical Engineering, Petroleum Training Institute, Effurun, Nigeria

${ }^{2}$ Department of Mechanical Engineering, Federal University of Petroleum Resources, Effurun, Nigeria

DOI: $10.36347 /$ sjet.2020.v08i04.003

| Received: 08.10.2019 | Accepted: 15.10.2019 | Published: 22.04.2020

*Corresponding author: Oyejide O.J

\section{Abstract}

Original Research Article

This paper presents the development of software for exergy analysis of gas turbine. The turbine plant consists of an air compressor, combustion chamber and turbine unit. In the development of the software, flowcharts and algorithm were developed to aid the coding of the software. Visual basic.net (6.0) programming tool was used as the programming language in coding the software. Data was collected from the external operator log sheet and panel operator log sheet of the gas turbine unit, power plant and utilities department of Warri Refinery and Petrochemical Company, EkpanWarri, Nigeria. An analysis was carried out using manual computation and subsequently the developed software was used to perform same analysis. Several verification tests carried out using the developed software showed that the software result is consistently close to $100 \%$ accuracy. The results obtained for the combustion and turbine unit of the plant indicates that the combustion chamber has the highest exergy efficiency $(94.20 \%)$ while the highest exergy losses $(13.18 \%)$ occurred at the turbine unit.

Keywords: Exergy, combustion chamber, exergy efficiency, exergy losses, gas turbine.

Copyright @ 2020: This is an open-access article distributed under the terms of the Creative Commons Attribution license which permits unrestricted use, distribution, and reproduction in any medium for non-commercial use (NonCommercial, or CC-BY-NC) provided the original author and source are credited.

\section{INTRODUCTION}

The efficient use of energy resources in developing countries like Nigeria has become increasingly important due to her rising population. To ensure steady and stable power supply which is one of the panaceas for economic growth, there must be instantaneous and rapid deployment of computer technology to facilitate efficient maintenance of power plants. However, electricity which is usually the mainstay of the economy of a nation has been a major problem in Nigeria due to the low output (less than $40 \%$ ) of the power plants in the country.

Gas turbine also known as combustion turbine is the most commonly used generation plant for electricity. It is a rotary engine that removes energy from a flow of combustion of gas. It has an upstream compressor connected to a downstream turbine of a combustion chamber connected in between. Energy is released when the air is mixed with fuel and ignited the combustor (1-3).

Exergy is the maximum (useful) work that is available (obtained) from a system or process. In any system (plant) just as there is useful energy so also there are losses. The reason being that no system is $100 \%$ efficient [4-5]. Exergetic analysis identifies the components of the system which are at the origin of the exergy losses and is based on the exergy concept. The exergy concept is related to the energy and the reversible character of a process [6]. Haseli et al. [7], defined exergy analysis as an effective thermodynamic scheme for using the conservation of mass and energy principles together with the second law of thermodynamics for the design and analysis of thermal systems by reducing its inefficiencies. Abam et al. [8] conducted an exergy analysis on a $138 \mathrm{MW}$ gas turbine plant with data obtained from plant operation. They investigated the effect of ambient temperature on the performance of the components of the gas turbine plant using the exergy concept, to identify components that offer significant work potential saving opportunity. The overall exergy loss was evaluated and the results were $83.47 \%$ and $84.56 \%$ for ambient temperature values of 295 and 307K respectively. Shalan et al. [9] employed a simple methodology to estimate parameters of Rowen's model for heavy duty single shaft gas turbines. The parameters of the model were derived using the performance and operational data. Variety of simulated tests was performed in SIMULINK/MATLAB environment and the results were compared with and verified against the results of involved scientific articles in the literature. The parameters of a single- shaft heavy duty gas turbine were estimated using its operational 
data based on Rowen's model by Tavakoli et al. [10]. In another study, Isam [11] carried out an analysis of the energy and exergy of Al-Hussein power plant in Jordan that has capacity of $396 \mathrm{MW}$. The plant performance was evaluated by a component wise modeling and an exhaustive break-up of energy and exergy wastes for the considered plant was been exposed. Main losses of energy happened in the condenser where $134 \mathrm{MW}$ is lost to the surrounding while only $13 \mathrm{MW}$ was lost from the boiler system. The exergy destruction percentage ratio to the total exergy waste was discovered to be maximum in the boiler system $(77 \%)$ followed by the turbine (13\%), and then the enforced flow fan condenser (9\%). Additionally, the calculated thermal efficiency depends on fuel lower heating value which was $26 \%$ whereas the power cycle exergy efficiency was $25 \%$.

However, in exergy analysis of mechanical systems, there is usually a large volume of operational data from the various devices and sections of the plant to deal with. This makes it often difficult to embark on manual analysis and evaluation of these plants exergy due to the fact that manual computation can be very tedious, cumbersome, error prone and time consuming. To minimise these laborious task and human computational errors, the use of appropriate computer tool could facilitate effective and efficient analysis of gas turbine exergy.

\section{METHODOLOGY Data Collection}

The data used in this study were collected from the external operator log sheet and panel operator log sheet of the gas turbine unit, power plant and utilities department of Warri Refinery and Petrochemical Company, Ekpan-Warri, Nigeria. The data collected include the temperature of air, flue gases and exhaust gases, pressure of air, flue gases, exhaust gases, and mass flow rate of fuel, air and exhaust gases and these data span from January to June, 2016.

\section{DATA ANALYSIS}

The data presented in the Table 1 was analyzed to determine the exergy and exergy efficiency of the air compressor, combustion chamber and gas turbine; exergy destruction and exergy destruction efficiency of the air compressor, combustion chamber and gas turbine. Also the overall plant exergy, overall plant exergy efficiency, total exergy destroyed and overall plant exergy destruction efficiency. These analyses were done using Equations 1 to 38 for the period of January - June 2016.

\section{Thermal Exergy at State 1}

The thermal exergy at state 1 is given by Equation (1) as follows:

$$
E_{1}^{T}=\frac{m_{a} c_{p_{a}}\left[t_{1} t_{r e f}\right] t_{r e f} \ln \frac{t_{1}}{t_{r e f}}}{1000}
$$

\section{Mechanical Exergy at State 1}

The mechanical exergy at state 1 is given by Equation (2)

$$
E_{1}^{M}=\frac{\left(m_{a} \cdot R_{a} \cdot t_{r e f} \ln \frac{P_{1}}{t_{r e f}}\right)}{1000}
$$

\section{Entropy at State 1}

The entropy at state 1 is given by Equation (3)

$$
S_{1}=\frac{\left(m_{a}\left[c_{p_{a}} \ln \frac{t_{1}}{t_{r e f}}-R_{a} \ln \frac{P_{1}}{P_{r e f}}\right]\right)}{1000}
$$

\section{Thermal Exergy at State 2}

The thermal exergy at state 2 is given by Equation (4)

$$
E_{2}^{T}=\frac{m_{a} c_{p_{a}}\left[t_{2}-t_{r e f}\right]-t_{r e f} \ln \frac{t_{2}}{t_{r e f}}}{1000}
$$




\section{Mechanical Exergy at State 2}

The mechanical exergy at state 2 is given by Equation (5)

$$
E_{2}^{M}=\frac{\left(m_{a} \cdot R_{a} \cdot t_{r e f} \ln \frac{P_{2}}{t_{r e f}}\right)}{1000}
$$

\section{Entropy at State 2}

The entropy at state 2 is given by Equation (6)

$$
S_{1}=\frac{\left(m_{a}\left[c_{p_{a}} \ln \frac{t_{2}}{t_{r e f}}-R_{a} \ln \frac{P_{2}}{P_{r e f}}\right]\right)}{1000}
$$

\section{Change in Thermal Energy of the Air Compressor}

The change in thermal energy of the air compressor is given by Equation (7)

$$
\Delta E^{T A C}=E_{1}^{T}-E_{2}^{T}
$$

\section{Change in Mechanical Exergy of the Air Compressor}

The change in mechanical exergy of the air compressor is given by Equation (8)

$$
\Delta E^{M A C}=E_{1}^{M}-E_{2}^{M}
$$

\section{Change in Entropy in the Air Compressor}

The change in entropy in the air compressor is given by Equation (9)

$$
\Delta S^{A C}=t_{r e f}\left[S_{1}-S_{2}\right]
$$

\section{Chemical Exergy}

The chemical exergy is given by Equation (10)

$$
E^{C H E}=\frac{\left(\left[1.0308+m_{f}\right] L H V\right)}{1000}
$$

\section{Heat loss in the Combustion Chamber}

The heat loss in the combustion chamber is given by Equation (11)

$$
Q_{C C}=\frac{\left(m_{e x h} C_{P e x h}\left[t_{3}-t_{2}\right]\right)}{1000}
$$

\section{Thermal Exergy of Fuel}

The thermal exergy of the fuel is given by Equation (12)

$$
E_{f}^{T}=\frac{m_{f} c_{p_{\text {NatG }}}\left[t_{f}-t_{r e f}\right]-t_{r e f} \ln \frac{t_{f}}{t_{r e f}}}{1000}
$$

Mechanical Exergy of Fuel

The mechanical exergy of fuel is given by Equation (13)

$$
E_{f}^{M}=\frac{\left(m_{f} R_{N_{a t G}} t_{r e f} \ln \frac{P_{f}}{P_{r e f}}\right)}{1000}
$$

\section{Entropy for Fuel}

The entropy for fuel is given by Equation (14)

$$
S_{f}=\frac{m_{f}\left[C_{P N a t G} \ln \frac{t_{f}}{t_{r e f}}-R_{N a t G} \ln \frac{P_{f}}{P_{r e f}}\right]}{1000}
$$




\section{Development of the Software}

The software was developed using Visual basic.net (6.0) and the data used was saved into test files. This is to ensure that the system will support good interface facilities with external programs and systems. The software was designed in such a way that the user interacts with the system through a series of input and dialog forms. The forms allow the user to input parameters or select the required parameters from a predefined list. The user enters only the values of the parameters and the system automatically generates the required results in the user interface. It also provides a user friendly interface consisting of menu bars and buttons to help user during data input to the system and facilitates explicit display of results. In addition, background colours, font sizes and font colours are carefully chosen to enhance the visual effect of the interfaces. The software developed is achieved by the following steps;

- Development of the Algorithm

- Coding of the Software

\section{Development of Algorithm for Exergy Analysis of Gas Turbine}

An algorithm is a specific set of instruction for carrying out a procedure or solving a problem, usually with the requirement that the procedure terminate at some point. The algorithm developed for the exergy analysis of the gas turbine is based on the flowcharts and consists of the sequence of obtaining the exergy efficiency and exergy destruction efficiency of the various components of the gas turbine.

\section{Coding of Software}

The software was coded using appropriate programming tool such as Visual basic.net. This is because of the unique characteristics of the programming language such as flexibility and ease of use through the adaption of modular approach. The screenshot of the main menu and interfaces for some computations such as Combustion chamber thermal exergy, Gas turbine inlet and outlet, exergy, exergy destruction and efficiencies of the various components of the gas turbine plant are shown in Fig. 2 to fig. 6.

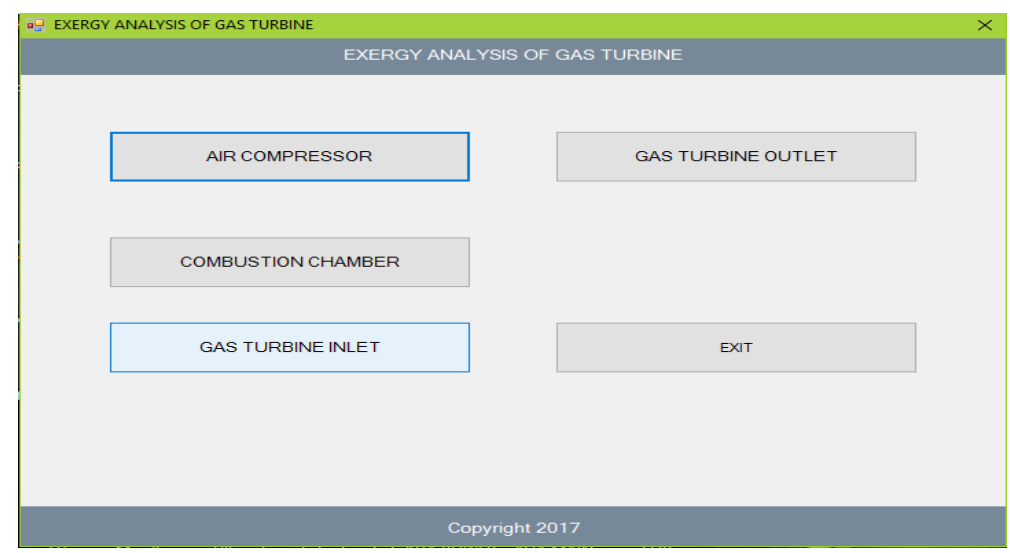

Fig-2: Screenshot of Main menu

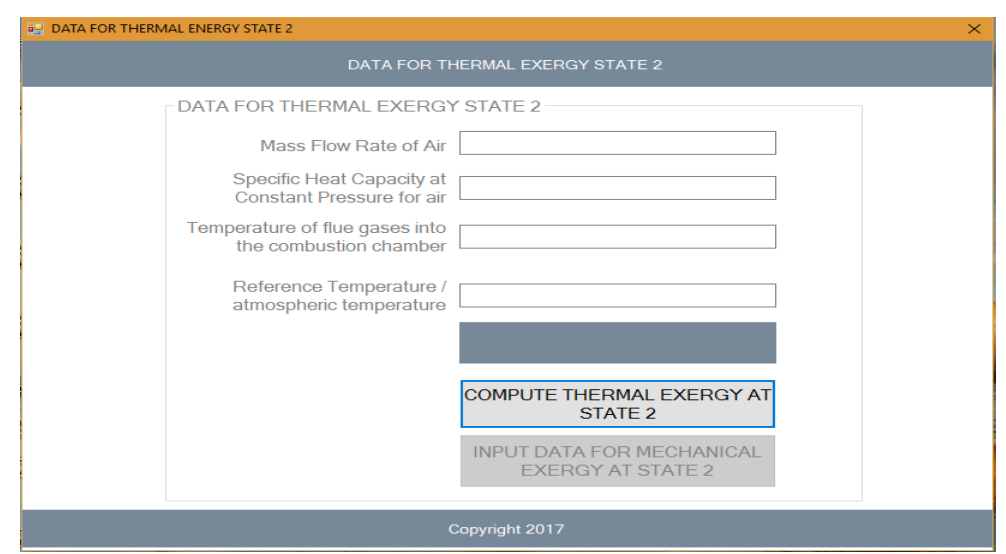

Fig-3: Screenshot of Interface for Computing Combustion Chamber Thermal Exergy 




Fig-4: Screenshot for Gas turbine inlet Interface

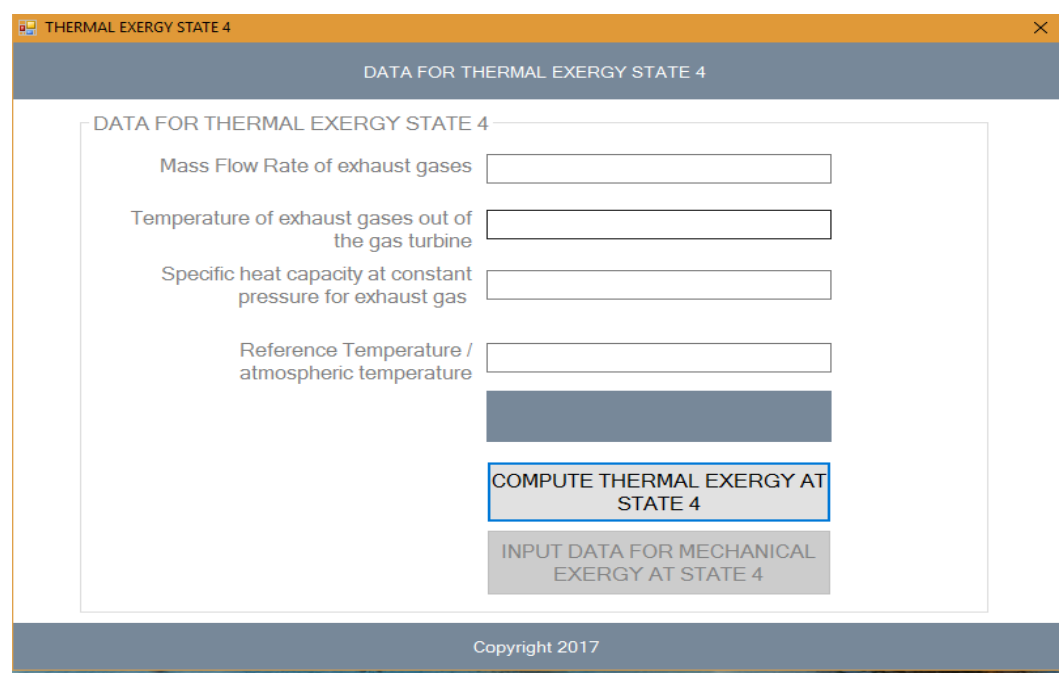

Fig-5: Screenshot for Gas turbine outlet Interface

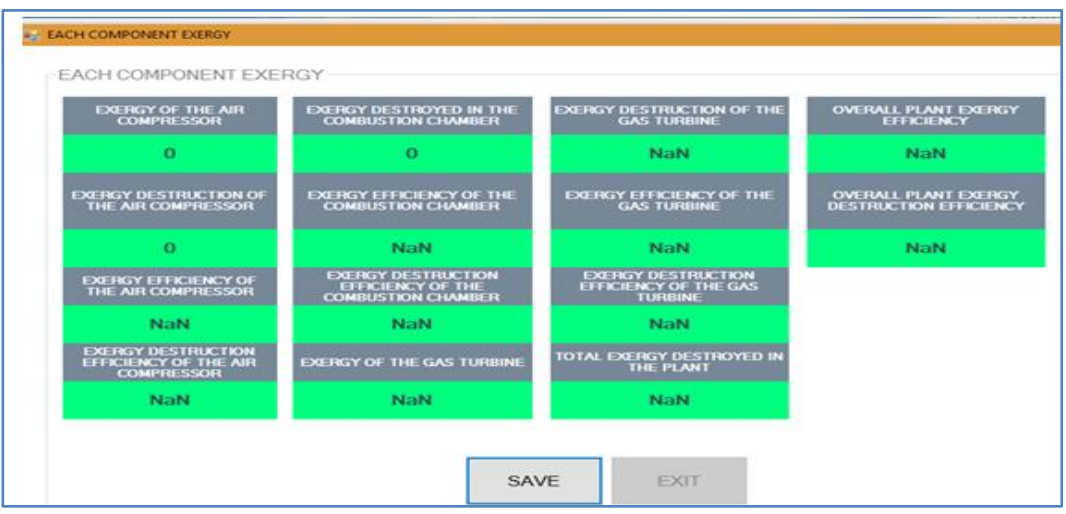

Fig-6: Screenshot for exergy, exergy destruction and efficiencies of the various components of the gas turbine plant

\section{RESULTS AND DISCUSSION}

This section presents the result obtained for the gas turbine exergy using manual computation and a developed software. Verification was carried out on the developed software using text cases and the results are presented in subsequent sections.

\section{Software Results for Exergy Analysis of Gas Turbine}

This section presents the result generated using the developed software. The results were verified using test cases and same data used for manual computations. The results obtained under various test cases are presented accordingly:

\section{Test Case 1: Thermal Exergy}

Significant input:

Mass flow rate of air $=120$

Specific heat capacity at constant pressure for air $=$ 1.005

Temperature of air into the air compressor $=383.67$

Reference/Atmospheric temperature $=300$

Output (Thermal Exergy) $=10.017$

FOR AIR COMPRESSOR (STATE ONE) 


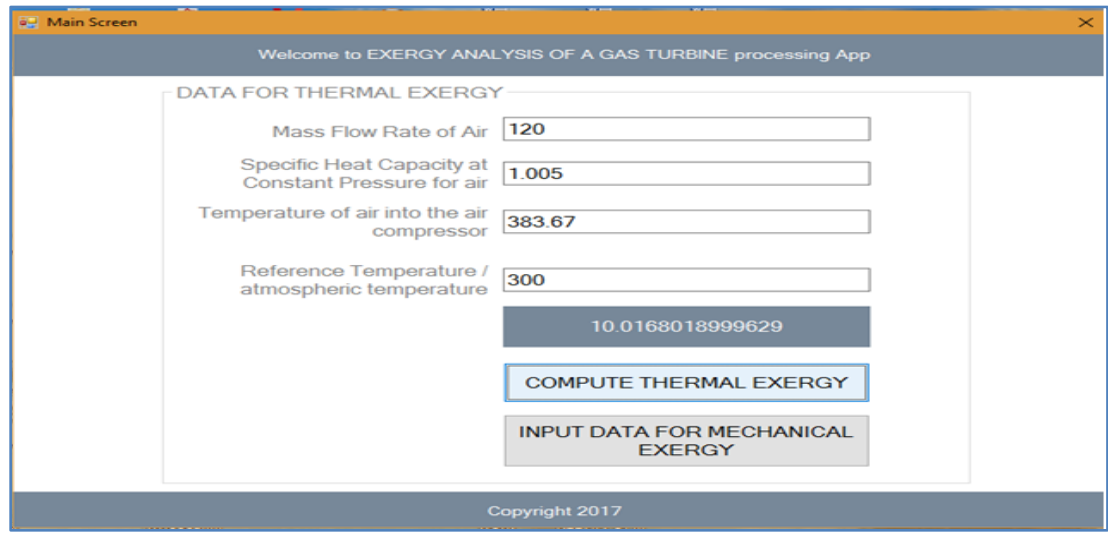

Fig-7: Screenshot of software result for Thermal Exergy

Test case 2: Mechanical Exergy

Significant input:

Mass flow rate of air $=120$

Pressure of air into the air compressor $=8$
Gas constant for air $=0.287$

Reference/Atmospheric temperature $=300$

Reference/Atmospheric pressure $=1.013$

Output $($ Mechanical Exergy $)=21.351$

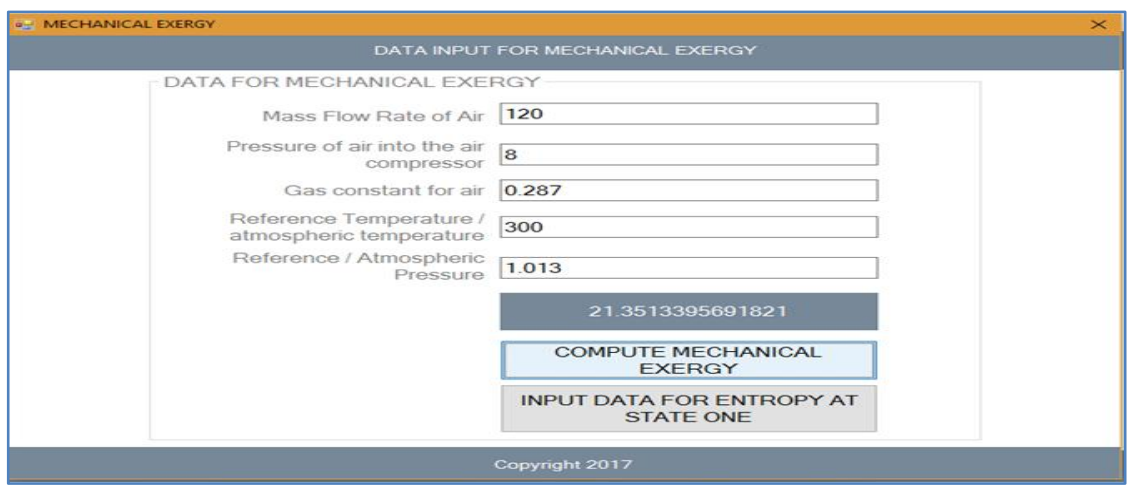

Fig-8: Screenshot of software result for mechanical exergy

A total of nineteen cases were examined during the software verification and the results obtained were compared to the results obtained manually as presented in Table 10.

Table-10: Comparative analysis of manual and software computation

\begin{tabular}{|l|l|l|l|}
\hline S/N & Components of gas turbine & $\begin{array}{l}\text { Manual } \\
\text { computation }\end{array}$ & $\begin{array}{l}\text { Software } \\
\text { computation }\end{array}$ \\
\hline 1 & Exergy of air compressor & 21.4 & 21.244 \\
\hline 2 & Exergy destruction of air compressor & 7.80 & 7.895 \\
\hline 3 & Exergy efficiencyof air compressor & 63 & 62.834 \\
\hline 4 & Exergy destruction efficiency of air compressor & 4 & 3.713 \\
\hline 5 & Exergy destruction of combustion chamber & 12.30 & 12.334 \\
\hline 6 & Exergy efficiency of combustion chamber & 94 & 94.2 \\
\hline 7 & Exergydestruction efficiency of combustion chamber & 6 & 5.8 \\
\hline 8 & Exergy of gas turbine & 77.85 & 77.683 \\
\hline 9 & Exergy destruction of gas turbine & 28.20 & 28.022 \\
\hline 10 & Exergy efficiency of gas turbine & 64 & 63.928 \\
\hline 11 & Exergy destruction efficiency of gas turbine & 13 & 13.178 \\
\hline 12 & Total exergy destroyed in the plant & 48.30 & 44.068 \\
\hline 13 & Overall plant exergy efficiency & 77 & 79.276 \\
\hline 14 & Overall plant exergy destruction efficiency & 23 & 20.724 \\
\hline
\end{tabular}

\section{DISCUSSION}

A comparative analysis of manual and software computations are presented in Table 10. and values obtained are the same except for slight deviations due to approximation. The computation carried out for exergy, exergy destruction and efficiencies of the gas turbine plant components using the developed software showed that the combustion chamber has the highest exergy efficiency $(94.2 \%)$ and 
the air compressor the lowest exergy efficiency $(62.834 \%)$. This implies that there is a complete combustion (proper air-fuel mixture) in the gas turbine plant. Also from the exergy efficiency of the air compressor, it shows that there is a pressure drop in the air that flows from the air compressor to the combustion chamber and this can also be as a result of the air compressor not properly seal or the rotor within the air compressor rotating at a low speed. Hence, the air compressor should be check regularly to see if there is any leakage and if found, should be sealed properly. Also, for an increase in the speed of the rotor, the rotating speed of the prime mover should be increased. The highest exergy destruction efficiency occurred in the turbine unit (13.18\%), and the lowest exergy destruction efficiency in the air compressor $(3.71 \%)$. This is as a result of improper lagging of the turbine unit or the temperature of the flue gas entering the turbine unit is not high enough. Therefore, to prevent such from occurring consistently, the maintenance team of the turbine plant should ensure that the turbine is properly lagged. Similarly, the exergy destruction efficiency of the air compressor shows that the energy supplied to the air compressor by the turbine unit through the rotating shaft was well utilized.

\section{CONCLUSION}

The development of software for exergy analysis of gas turbine turns out to be successful with a generated result that is consistently close to $100 \%$ accuracy. The results obtained shows that the combustion chamber has the highest exergy efficiency (94.2\%) while the air compressor unit has the lowest exergy efficiency $(62.834 \%)$. This implies that there is a complete combustion (proper air-fuel mixture) in the gas turbine plant. To increase the exergy of the air compressor which is the unit with the lowest exergy efficiency, the unit should be check regularly for any leakage and consequent repair action such as proper sealing carried out immediately. Moreover, since the highest exergy destruction efficiency occurred in the turbine unit $(13.18 \%)$ and the lowest exergy destruction efficiency in the air compressor unit $(3.71 \%)$, regular attention should be given to the gas turbine unit to minimize exergy losses (irreversibilities).

\section{RECOMMENDATIONS}

Based on the results obtained using the developed software, it is recommended that:

- The turbine unit should be lagged properly to avoid heat losses.

- The temperature of the flue gases entering the gas turbine should be increased so as to have an increase in the power output of the turbine and thus increase its exergy efficiency.

- The air compressor should be checked regularly to see if there is any leakage and if found, should be sealed properly immediately.

\section{REFERENCES}

1. Ukwamba SI, Orhorhoro EK, Omonoji AA. Performance Evaluation of a Simple Gas Turbine Power Plant Using Vapour Absorption Chiller. Journal of Mechanical and Civil Engineering (IOSR-JMCE). 2018; 15(2): 13-18

2. Ibrahim TK, Rahman MM, Abdalla AN. Improvement of gas turbine performance based on inlet air cooling systems: A technical review. International Journal of Physical Sciences. 2011; 6 (4): 620-627

3. Shi X, Agnew B, Che D, Gao J. Performance enhancement of conventional combined cycle power plant by inlet air cooling, inter-Cooling and LNG cold energy utilization. Applied Thermal Engineering. 2010; 30: 2003-2010

4. Zunaid M, Murtazab Q, Samshera. Energy and Second Law of Thermod ynamics Analysis of Shower Cooling Tower with Variation in Inlet Air Temperature. Interational Journal of Engineering: IJE TRANSACTIONS. 2017; 30(7): 1090-1097

5. Egware HO, Obanor AI, Exergy Analysis of Omotosho Phase I Gas Thermal Plant. International Journal of Engineering \& Technology Sciences (IJETS). 2013; 1(4): 206-217.

6. Haseli Y, Dincer I, Naterer G. Thermodynamics Analysis of a Combined Gas Turbine Power System with a Solid Oxide Fuel Cell through Exergy. Thermochimica Acta, Ontario, Canada. 2008; 480(1): 1-9.

7. Abam FI, Onyejekwe DC, Unachukwu GO. The Effect of Ambient Temperature on Components Performance of an In-serviceGas Turbine Plant using Exergy Method. Singapore Journal of Scientific Research. 2011; (1): 23-37. 